\title{
RESISTÊNCIA DE SETE GENÓTIPOS DE MILHO (Zea mays, L.) AO ATAQUE DE Sitophilus zeamais MOTSCHULSKY, 1855
}

SENÔ, Kenji Cláudio Augusto ${ }^{1}$

SEGATELLI, Ellis Kumotto ${ }^{2}$

PEREIRA, Frederico André Crotti ${ }^{2}$

MINE, Érica Tiemi ${ }^{2}$

NEVES, Murilo Coelho Theodoro ${ }^{3}$

SILVA, Pollyanna Tavares $\mathrm{da}^{3}$

Recebido em: 2009-02-05

Aprovado em: 2009-09-29

ISSUE DOI: $10.3738 / 1982.2278 .285$

RESUMO: O milho (Zea mays, L.) é um produto agrícola altamente cultivado em todo o território nacional, tendo sua utilização uso para consumo humano e animal, além de inúmeros derivados utilizados na produção e industrialização de alimentos. Assim como outros grãos cultivados no país, sofre o ataque de inúmeras pragas durante o seu desenvolvimento no campo e também durante o armazenamento, tendo entre os mais prejudiciais, os carunchos do gênero Sitophilus ssp. O objetivo deste trabalho foi avaliar a resistência ao ataque de S. zeamais MOTS., 1855, de sete genótipos de milho. Os resultados para as variáveis de redução de peso, número de carunchos ao final do ensaio, percentagem de ataque e redução do teor de nitrogênio, indicaram que os híbridos que melhor se destacaram quanto à resistência foram o C 701 (Cargill) e o AG3050 (Agromen), sendo os mais resistentes e indicados para locais com grande pressão de infestação.

Palavras-chave: Danos. Infestação. Caruncho. Ambiente controlado.

\section{RESISTANCE OF SEVEN GENOTYPES OF MAIZE (Zea mays, L.) TO THE ATTACK OF Sitophilus zeamais MOTSCHULSKY, 1855.}

SUMMARY: The maize (Zea mays, L.) is a highly agricultural product grown in the entire national territory, having its utilization use human and animal consumption, besides derivatives used in the production and industrialization of food. Like other grains grown in the country, suffers the attack of many pests during its development in the field and during storage, having among the most harmful, the weevil of the genus Sitophilus spp. The objective of this study was to evaluate the resistance of seven genotypes of maize to attack of $S$. zeamais MOTS., 1855. The results for the variables weight reduction, the number of weevil at the end test, percentage of the

${ }^{1}$ Professor Doutor Faculdade Dr. Francisco Maeda. FE/FAFRAM.

${ }^{2}$ Engenheiro Agrônomo. FE/FAFRAM

${ }^{3}$ Graduando em Engenharia Agronômica. FE/FAFRAM. 
attack and reduction of nitrogen content, indicated that the hybrids that best highlighted in the resistance were the $\mathrm{C}$ 701 (Cargill) and AG3050 (Agromen), being the most resistant and indicated for locations with high pressure of infestation.

Keywords: Damage. Infestation. Weevil. Controlled environment.

\section{INTRODUÇÃO}

O milho (Zea mays L.) constitui um dos principais insumos para o segmento produtivo, sendo utilizado com destaque no arraçoamento de animais, em especial na suinocultura, na avicultura e na bovinocultura de leite, tanto na forma "in natura" como na forma de farelo, de ração ou de silagem. Na alimentação humana, o milho é comumente empregado na forma "in natura", como milho verde, e na forma de subprodutos, como pão, farinha e massas (BULL; CANTARELLA, 1993) além de fazer parte de inúmeros produtos alimentícios na forma de estabilizantes, modificadores de consistência ou nutricionais.

A colheita deve ser realizada quando os grãos estiverem na fase final de endurecimento, entre 40 e 50 dias após o florescimento, e teor de umidade entre 17 e $18 \%$ (por cento) para evitar perdas, procedendo-se à secagem em terreiros ou silos ventilados. Para que não ocorra deterioração, o milho deve ser armazenado com umidade máxima de 13\%. (DENUCCI et al., 1999).

Devido à importância da cultura, a preocupação com a produção e armazenamento do grão deve ser tomada como prioridade, principalmente em relação às perdas por insetos em armazenamento. Essas pragas podem causar uma perda de até $20 \%$, o que é considerado bastante significativo. Os insetos causam perdas quantitativas e qualitativas, afetando também a porcentagem de germinação e valor nutritivo (FACELLI; LIMA apud SOLA, 1996).

As espécies do gênero Sitophilus (Coleoptera, Curculionidae), que danificam grãos armazenados, são algumas das mais importantes pragas conhecidas (MATIOLI et al.).

De acordo com Büll e Cantarella (1993), o caruncho do milho, Sitophilus zeamais Mots., juntamente com o caruncho do arroz, Sitophilus oryzae (Linnaeus), constituem as principais pragas de cereais (milho, arroz, trigo, sorgo, e outros) armazenados no Brasil.

Este inseto, ao romper o grão, facilita a infestação do mesmo e por outras espécies que possuem mandíbulas menos resistentes. Os estados biológicos em que ataca e destrói os grãos armazenados são larva e adulto (COMPANHIA ESTADUAL DE SILOS E ARMAZÉNS, 1974).

Nucleus, v.6, n.2, out. 2009 
Todos os insetos que atacam grãos armazenados caracterizam-se pela alta capacidade de se reproduzir. O elevado número de indivíduos obtidos em cada reprodução e o grande número de gerações capazes de se dar num curto período permite que poucos indivíduos, em pouco tempo, formem uma população considerável, o que leva a acreditar que uma pequena infestação pode danificar, em poucos meses, grande quantidade dos grãos armazenados (PUZZI, 1977).

Segundo Puzzi (1986), a fêmea, utilizando as peças bucais, faz um orifício no grão, onde deposita um só ovo de cada vez, fechando em seguida o orifício com uma espécie de gelatina. Dos ovos nascem pequenas larvas de cor creme, com a cabeça castanha, as quais começam a alimentar-se e desenvolver-se no interior do grão. No estágio de pupa, o inseto torna-se imóvel e não se alimenta por alguns dias, transformando-se em seguida em inseto adulto. Cada fêmea pode pôr até 150 ovos durante sua vida, e em condições ótimas de temperatura e umidade relativa, $28^{\circ} \mathrm{C}$ e $70 \%$ de U.R., o ciclo evolutivo da postura ao adulto, pode ser realizado entre 4 a 5 semanas.

Segundo a FAO (Food and Agriculture Organization), as quantidades das perdas são variáveis de país para país e de ano para ano, mas na Índia, parte da África e em alguns países da América do Sul, é estimado que $30 \%$ das colheitas são perdidas. No Brasil, a rápida comercialização dos cereais e grãos leguminosos, produzidos nestes últimos anos, constitue um óbice para avaliar, com relativa precisão, a magnitude das perdas (PUZZI, 2000).

Miranda et al. (1995) correlacionando a presença de $S$. zeamais e a ocorrência de outros insetos na espiga, indica que com o ataque de Helicoverpa zea (Bod.) (Lepidóptera, Noctuidae), a barreira mecânica exercida pela palha do milho é quebrada, permitindo o acesso de outros insetos como o Cathartus quadricollis (Guérin) (Coleóptera, Cucujidae) que, juntamente com o $S$. zeamais é favorecido pelo rompimento da palha.

Os métodos físicos para controle de pragas estão se tornando mais relevantes, recebendo atenção por parte dos pesquisadores, indústria e consumidores. Os problemas resultantes das atuais práticas de controle empregadas nas unidades armazenadoras e nas áreas domissanitárias têm contribuído para a redução dos inseticidas químicos. Dos métodos físicos empregados para o controle de insetos, o uso de pó inerte tem-se mostrado como um produto eficaz e de baixos riscos para o meio ambiente e o homem. O solo diatomáceo mostrou-se eficiente e seguro para ser utilizado como um componente de programas de manejo integrado de pragas e promoveu longos períodos de proteção, sendo eficiente no controle de Sitophilus spp pelo período de um ano (PINTO JÚNIOR, 1999). 
Resultados obtidos por Afonso (2001), mostram que as concentrações médias de $\mathrm{O}_{2}$ (aproximadamente $4,0 \%$ em volume nas cinco primeiras semanas do experimento) e de $\mathrm{CO}_{2}$ (aproximadamente 13,4\%) obtidas no interior do silo, foram adequadas para controlar as pragas que infestam os grãos armazenados. Observou-se que a partir do trigésimo dia sob efeito da atmosfera produzida, a geração $\mathrm{F}_{1}$ do $S$. zeamais reduziu a sua postura e, conseqüentemente, o seu desenvolvimento, resultando em um controle de $91,1 \%$ na geração $\mathrm{F}_{2}$.

Rosseto (1973), define planta resistente como aquela que devido à sua constituição genotípica é menos danificada que uma outra, em igualdade de condições.

A elevada incidência de insetos-praga tanto na safrinha como na safra normal tem acarretado uso intensivo de inseticidas, elevando os custos de produção, aumento de resíduos tóxicos no grão e ocorrência de intoxicações de homens e animais (GUEDES, 1990/1991). Para minimização desses problemas, deve-se buscar o uso de outros métodos de controle, como o uso de variedades resistentes às pragas. Para o desenvolvimento de variedades resistentes às pragas, são necessários estudos sobre a detecção de genótipos que sirvam como fonte de resistência (PICANÇO et al., 2003).

Miranda observou que as populações Híbridas Bonfinópolis, Caiano (Sobrália), Dente de Rato, Bico de Ouro, Sabugo Pino, Brancão, Palha Roxa (Celso Sul de Minas) e BR 451 foram altamente preferidas no campo, apresentando, entretanto, grãos pouco preferidos. Isto demonstra a ocorrência de substâncias voláteis presentes na palha e/ ou cabelo do milho que podem influenciar na atratividade desses insetos.

O presente trabalho teve como objetivo estudar as perdas ocasionadas pelo caruncho do milho (Sitophilus zeamais) em 7 variedades diferentes de milho em condições de ambiente controlado.

\section{MATERIAL E MÉTODOS}

O experimento foi conduzido no Laboratório de Sementes e Sistemática Vegetal, da Faculdade "Dr. Francisco Maeda" - FAFRAM-Ituverava, SP, região da Alta Mogiana. Optou-se por utilizar a Estufa tipo B.O.D. com finalidade de maior controle das variáveis ambientais e permitir mantê-lo o mais próximo possível das condições dos grãos no armazenamento. Além disso, a variação em temperatura e umidade, dentro da massa de grãos, torna algumas áreas mais vantajosas para os insetos que outras, sendo assim a variabilidade em quantidades de insetos, 
entre duas amostras de grão do mesmo local, são tão grandes quanto entre quadrantes diferentes de um silo ou entre silos, de acordo com CUPERUS et al. (1990), efeito esse que foi eliminado com o uso da B.O.D.

Foram utilizados os seguintes genótipos para teste:

- AL BANDEIRANTE (CATI)

\begin{tabular}{|l|l|l|l|}
\hline Nível tecnológico & Tipo & Ciclo & Região \\
\hline Médio/ Alto & Variedade & Precoce & Brasil \\
\hline
\end{tabular}

- EXCELER (Syngenta)

\begin{tabular}{|c|l|l|l|}
\hline Nível tecnológico & Tipo & $\underline{\text { Ciclo }}$ & $\underline{\text { Região }}$ \\
\hline Médio/ Alto & HT & Precoce & CO e SE, BA, MA, PI, TO. \\
\hline
\end{tabular}

- AG 3050 (Agromen)

\begin{tabular}{|c|c|c|l|}
\hline Nível tecnológico & $\underline{\text { Tipo }}$ & $\underline{\text { Ciclo }}$ & $\underline{\text { Região }}$ \\
\hline Médio/ Alto & HS & Superprecoce & SUL, RO e BA, MA ,MG, PI, RJ, TO, SP. \\
\hline
\end{tabular}

- C 701 (Cargill)

\begin{tabular}{|l|l|l|l|}
\hline$\underline{\text { Nível tecnológico }}$ & $\underline{\text { Tipo }}$ & $\underline{\text { Ciclo }}$ & $\underline{\text { Região }}$ \\
\hline Médio/ Alto & HD & Precoce & S/CO/SE, RO,TO, MA, PI, CE e oeste da BA. \\
\hline
\end{tabular}

- $2 \mathrm{C} 577$ (Dow AgroSciences)

\begin{tabular}{|c|l|l|l|}
\hline Nível tecnológico & $\underline{\text { Tipo }}$ & $\underline{\text { Ciclo }}$ & $\underline{\text { Região }}$ \\
\hline Médio/ Alto & HS & Precoce & Tropical baixa $<500 \mathrm{~m}$ de altitude, RS, SC PR., \\
\hline
\end{tabular}

- DKB 929 (Monsanto)

\begin{tabular}{|c|l|l|l|}
\hline Nível tecnológico & $\underline{\text { Tipo }}$ & $\underline{\text { Ciclo }}$ & $\underline{\text { Região }}$ \\
\hline Alto & HSM & Precoce & S/CO/SE, RO,TO, MA, PI, CE e oeste da BA. \\
\hline
\end{tabular}

- $\quad$ FORT (Syngenta)

\begin{tabular}{|c|l|l|l|}
\hline Nível tecnológico & $\underline{\text { Tipo }}$ & $\underline{\text { Ciclo }}$ & $\underline{\text { Região }}$ \\
\hline Alto & HSM & Precoce & S/CO/SE, RO,TO, MA, PI, CE e oeste da BA. \\
\hline
\end{tabular}

Obrigatoriamente, nenhuma das amostras sofreu expurgo ou qualquer tipo de aplicação de produto químico, além de estarem isentas de infestação.

Para testar o efeito do S. zeamais no peso e na qualidade dos grãos, inicialmente foram pesados 90,0 gramas de cada cultivar, as quais foram acondicionadas em placas de Petri, liberando-se em seu interior 15 insetos adultos. Posteriormente foram fechadas e vedadas com fita adesiva para evitar a fuga dos insetos. Em cada cultivar foram efetuadas 5 repetições, perfazendo um total de 35 placas para teste, submetidas à ambiente controlado, em B.O.D, com temperaturas entre 26 e $28^{\circ} \mathrm{C}$, por 93 dias. 
O delineamento experimental utilizado foi de blocos inteiramente casualizados, avaliados pelo teste de Tukey.

No caso dos dados expressos em porcentagem foi utilizada transformação pela fórmula arc sen $\sqrt{\frac{x+\alpha}{100}}$, sendo $\alpha=0,50$ e número de observações $($ N.obs $)=28$. Para as demais análises não foram utilizadas transformações. Para fins de cálculo foi descartada a repetição mais discrepante do genótipo, sendo realizado em todos os tratamentos.

Após o encerramento do ensaio, 92 dias, a avaliação foi realizada através da contagem do número de carunchos, pesagem de grãos no final do ensaio, contagem de grãos danificados e envio de amostras de grãos das repetições dos genótipos para análise de proteína no laboratório de Fertilidade do Solo e Análise de Plantas da FAFRAM.

\section{RESULTADOS E DISCUSSÃO}

A seguir, observa-se a análise estatística e os gráficos dos resultados, com as médias de grãos danificados, perda de peso, número de carunchos, teor de proteína e teor de nitrogênio.

A análise estatística foi altamente significativa pelo teste de Tukey a $1 \%$ de probabilidade. O genótipo C 701 foi o material mais resistente para desenvolvimento populacional dos carunchos, onde se observou a menor média de quantidade (56,25 carunchos), podendo citar também o genótipo AG3050 por sua média baixa. Estes resultados foram opostos aos encontrados por Boiça Júnior; Lara; Guidi (1997), em que o genótipo C 701 comparado com outros genótipos, foi o mais suscetível, porém com baixa atratividade. De acordo com Painter (1951), que descreveu os tipos de resistências, neste ensaio não se colocou chance de escolha ao inseto e ao desenvolvimento obrigatório dos carunchos sobre o genótipo escolhido, levando a uma provável resistência por antibiose.

A diferença dos resultados obtidos entre Boiça Júnior; Lara; Guidi (1997) e este ensaio, provavelmente se explica pelo fato de se ter comparado com genótipos diferentes, e de acordo com Lara (1991), a resistência é sempre comparativa. A maior população de carunchos foi registrada no genótipo DKB 929, com média de 222,25 carunchos, mas que estatisticamente não diferiu dos demais genótipos, exceto os dois já citados (C 701 e AG 3050).

Outra estatística foi altamente significativa, ao nível de 1\%. O genótipo com maior média de porcentagem de grãos danificados $(87,8 \%)$ foi $2 \mathrm{C} 577$, mas que acabou diferindo 
estatisticamente apenas dos genótipos AG 3050 (28,4\%) e C 701 (15,9\%). Portanto, os genótipos que expressaram melhor qualidade neste caso foram AG 3050 e C 701, devido suas menores médias de danos.

A análise estatística foi altamente significativa, ao nível de $1 \%$. A menor redução de peso ocorreu com os genótipos C 701 (3,61 g) e AG 3050 (4,95 g), em relação aos demais genótipos, exceto com DKB 929, FORT, AL BAND, onde, estatisticamente não se observou diferença. O genótipo onde houve uma maior redução de peso foi 2C 577 (16,9 g). Assim, os genótipos com maior índice de qualidade foram C 701 e AG 3050, devido a menor perda de peso registrada.

\begin{tabular}{cc}
\hline TRATAMENTOS & MÉDIAS \\
\hline DKB 929 & $222,25 \mathrm{~A}$ \\
2C 577 & $189,25 \mathrm{AB}$ \\
EXCELER & $169,25 \mathrm{ABC}$ \\
AL BAND & $162,00 \mathrm{ABC}$ \\
FORT & $150,00 \mathrm{ABC}$ \\
AG 3050 & $68,50 \mathrm{BC}$ \\
C 701 & $56,25 \quad \mathrm{C}$ \\
& \\
\hline DMS & 127,4728 \\
CV\% & 38,15 \\
\hline
\end{tabular}

F Tratamentos $=4,89 * *$

QUADRO 1. Médias do número de carunchos dos genótipos avaliados em laboratório. Ituverava, SP. 2003.

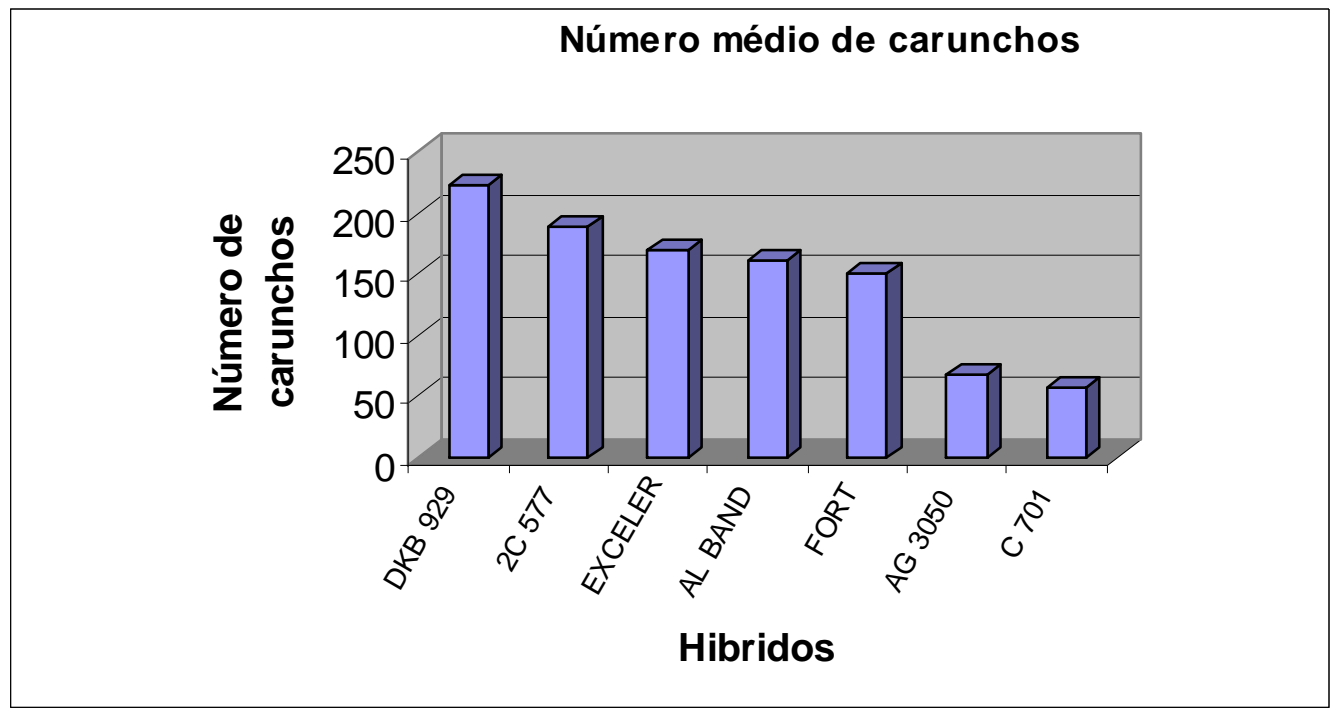

GRÁFICO 1. Comparação das médias do número de carunchos nos genótipos. Ituverava, SP. 2003. 


\begin{tabular}{cl}
\hline TRATAMENTOS & MÉDIAS $^{\mathbf{1}}$ \\
\hline 2C 577 & $87,8353 \mathrm{~A}$ \\
EXCELER & $72,6331 \mathrm{AB}$ \\
FORT & $71,8416 \mathrm{AB}$ \\
DKB 929 & $71,6049 \mathrm{AB}$ \\
AL BAND & $63,3710 \mathrm{AB}$ \\
AG 3050 & $28,3787 \quad \mathrm{BC}$ \\
C 701 & $15,9063 \quad \mathrm{C}$ \\
& \\
\hline DMS & 46,6419 \\
CV\% & 34,51 \\
\hline
\end{tabular}

1 valores expressos em porcentagem (\%)

$\mathrm{F}$ Tratamentos $=6,73 * *$

QUADRO 2. Porcentagem média de grãos de genótipos danificados por ataque de caruncho, avaliados em condições de laboratório. Ituverava, SP. 2003.

Dados transformados em arc sen $\sqrt{\frac{x+\alpha}{100}}$

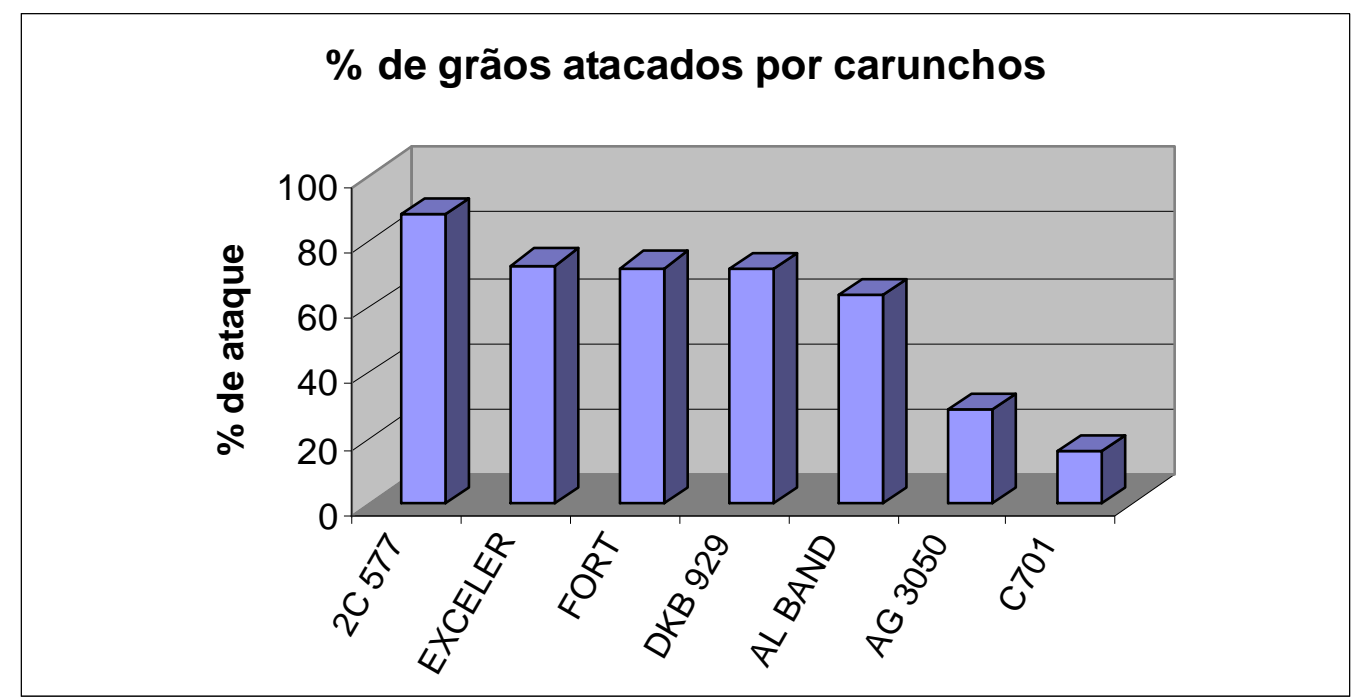

GRÁFICO 2. Comparação das médias de grãos danificados dos genótipos. Ituverava, SP. 2003. 


\begin{tabular}{cc}
\hline TRATAMENTOS & MÉDIAS \\
\hline 2C 577 & $16,9000^{1} \mathrm{~A}$ \\
EXCELER & $14,9075 \mathrm{~A}$ \\
DKB 929 & $13,4450 \mathrm{AB}$ \\
AL BAND & $13,2750 \mathrm{AB}$ \\
FORT & $12,0250 \mathrm{ABC}$ \\
AG 3050 & $4,9500 \mathrm{BC}$ \\
C 701 & $3,6125 \quad \mathrm{C}$ \\
& \\
\hline DMS & 9,3939 \\
CV\% & 36,16 \\
\hline
\end{tabular}

${ }^{1}$ Valores expressos em gramas $(\mathrm{g})$

$\mathrm{F}$ Tratamentos $=6,10 * *$

QUADRO 3. Médias de Redução de peso de grãos dos genótipos avaliados em condições de laboratório. Ituverava, SP. 2003.

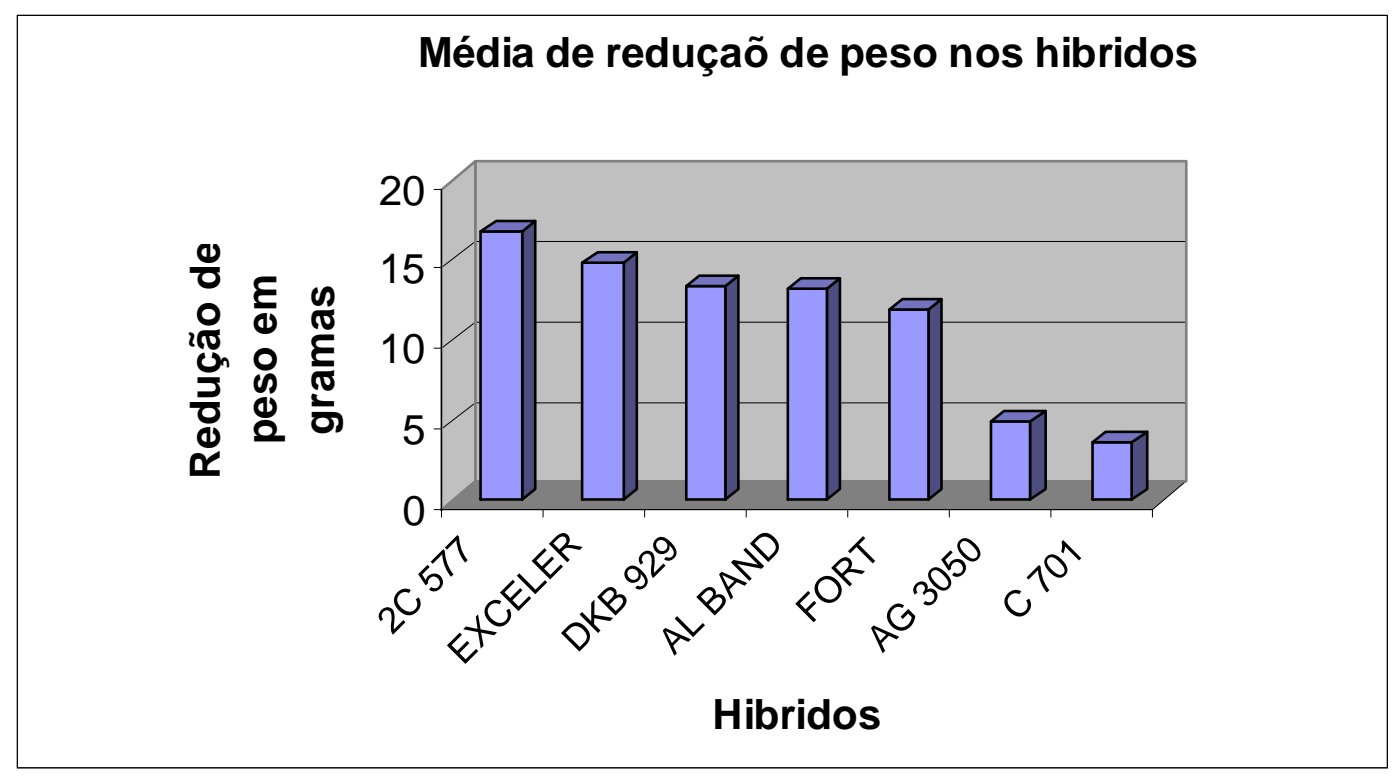

GRÁFICO 3. Comparação das médias de perda de peso em condições de laboratório. Ituverava, SP. 2003.

\subsection{Redução do Teor de Proteína}

As médias relativas aos teores de proteína não foram significativamente diferentes comparadas pelo teste de Tukey a $1 \%$ de probabilidade. $\mathrm{Na}$ amostra foram retirados todos os indivíduos (carunchos). 
Lopes et al. (1990), testando o efeito da infestação do caruncho no milho sobre a digestibilidade da proteína para suínos em crescimento relatou que, em análises químicas de Lopes et al. (1988), identificaram no milho com 5\%, 20\%, 30\%, 40\% e 50\% de carunchamento, um aumento no nível de proteína $(7,59 \%, 8,24 \%, 8,61 \%$ e 9,13\%). Com isto acredita-se que este aumento tenha sido provocado pela presença do próprio caruncho triturado junto com o milho, confirmando informações de Ibaragon (1959), sendo esta uma proteína de baixa digestibilidade, com elevação principalmente de aminoácidos não essenciais para suínos.

Gee (1972), em análise química do milho danificado por carunchos, verificou, em primeiro lugar, que eles se alimentam mais de proteína do milho do que de outros componentes, em segundo lugar, a maior destruição é de amido.

\begin{tabular}{cl}
\hline TRATAMENTOS & MÉDIAS $^{\mathbf{1}}$ \\
\hline DKB 929 & $35,9314 \mathrm{~A}$ \\
FORT & $35,1603 \mathrm{~A}$ \\
AL BAND & $32,6656 \mathrm{~A}$ \\
2C 577 & $29,3117 \mathrm{~A}$ \\
EXCELER & $28,0240 \mathrm{~A}$ \\
AG 3050 & $25,4251 \mathrm{~A}$ \\
C 701 & $25,3545 \mathrm{~A}$ \\
& \\
\hline DMS & 31,3674 \\
CV\% & 45,09 \\
\hline valores expressos em porcentagem $(\%)$ & \\
F Tratamentos $=0,41$ NS &
\end{tabular}

QUADRO 4. Médias de redução do teor de proteína dos genótipos avaliados em condições de laboratório. Ituverava, SP. 2003.

Dados transformados em arc sen $\sqrt{\frac{x+\alpha}{100}}$ 


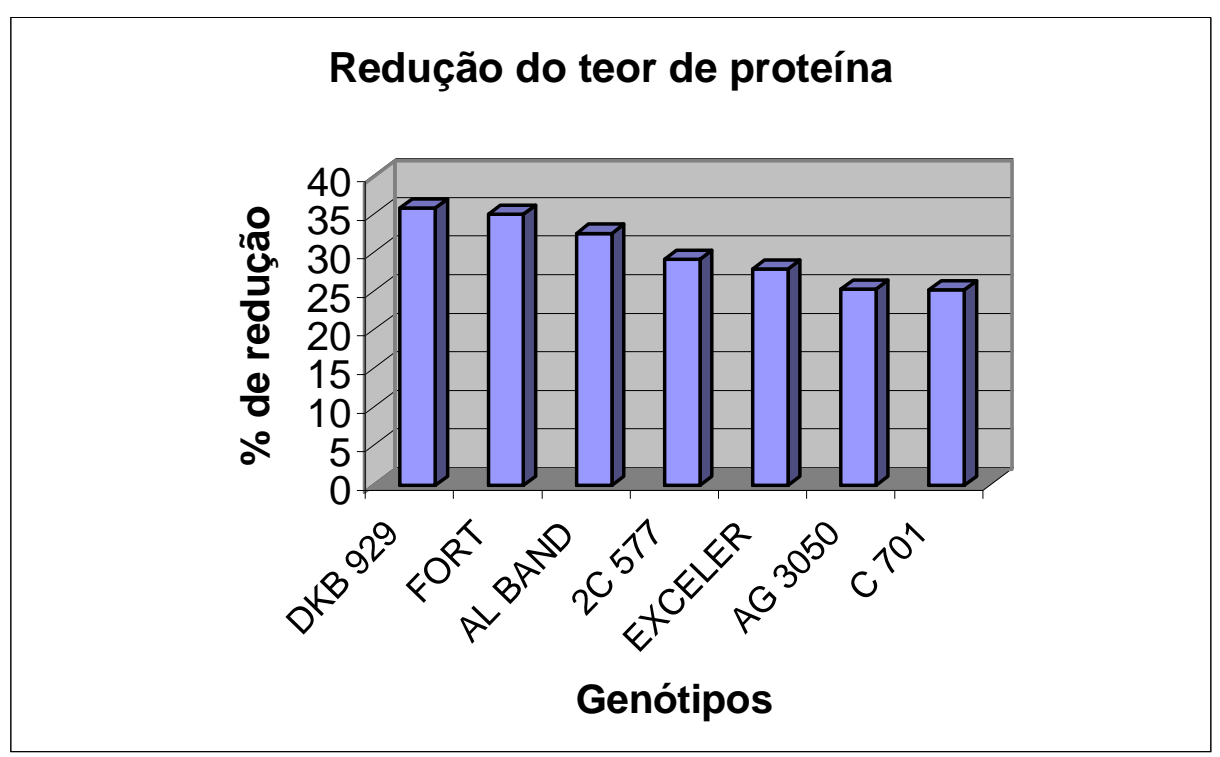

GRÁFICO 4. Comparação das médias de redução do teor de proteína.

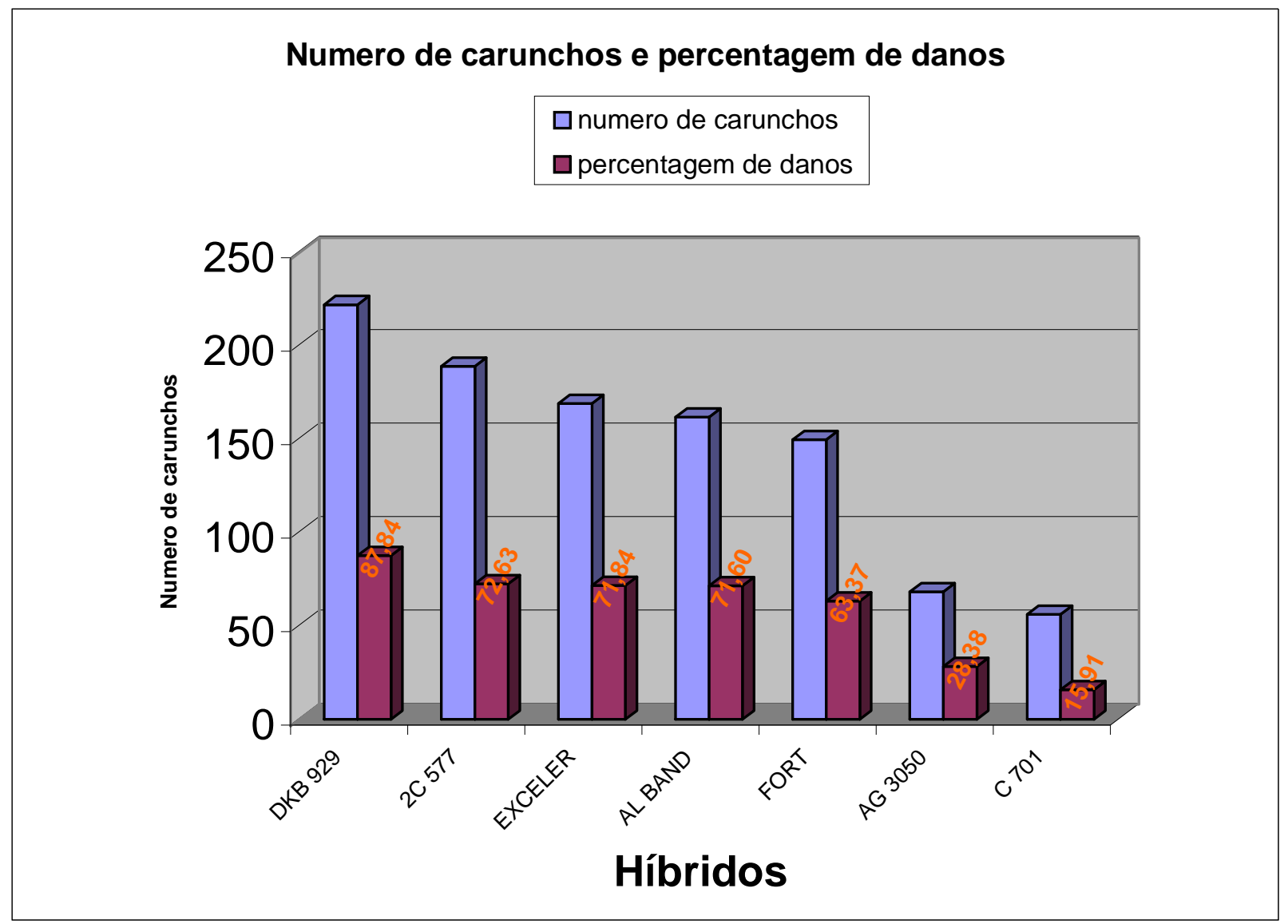

GRÁFICO 5. Relação das médias de Número de Carunchos e percentagem de danos. 
Com base nestes resultados, pode-se observar também que o menor ataque nos genótipos AG 3050 e C 701 pode estar relacionado com a resistência destes materiais ao caruncho, seja por alguma substância química ou até mesmo pela textura do grão, caracterizando a resistência por antibiose, que inibe a alimentação e reprodução desta praga.

Tais resultados não devem ser aplicados diretamente a campo, sem estudo prévio, devido o desenvolvimento do experimento ter ocorrido em condições ideais de temperatura e umidade para o desenvolvimento do caruncho. A campo, temos que considerar as condições adversas, e também o histórico da região, podendo esta ter ou não uma grande pressão de infestação do caruncho.

Outra variável a ser considerada é o manejo pós-colheita, imprescindível para evitar perdas por esta e outras pragas.

\section{CONCLUSÃO}

Os cultivares que melhor se destacaram quanto à resistência para as características avaliadas foram o C 701 e o AG 3050, sendo recomendados para locais com grande pressão de infestação de Sitophilus zeamais.

\section{REFERÊNCIAS}

BOIÇA JÚNIOR, A.L., LARA, F.M., GUIDI, F.P. Resistência de genótipos de milho ao ataque de Sitophilus zeamais Mots. (Coleoptera: Curculionidae). Anais... Soc. Entomol. Brasil v.26, n. 3 p. 481-485, 1997.

BÜLL, L.T; CANTARELLA, H. Cultura do milho: fatores que afetam a produtividade. Piracicaba. POTAFOS, 1993. p.02.

COMPANHIA ESTADUAL DE SILOS E ARMAZÉNS. Grãos: beneficiamento e armazenagem. Porto Alegre, 1974, p 40-42.

CUPERUS, G.W.; FARGO, W.S.; FLINN, P. W. Variables affecting capture of stored- grain insects in pobre Traps. J. Kans. Entomol. Soc., v. 63, p. 486- 489, 1990.

LARA, F.M. Princípios de resistência de plantas aos insetos. 2. ed. São Paulo: Ícone, 1991. 36p; p. 82; 111; 154; 155; 286; 289. 
LOPES, D.C.et al. Efeitos do nível de carunchamento do milho sobre a digestibilidade de sua proteína e energia para suínos em crescimento. R. Soc. Bras. Zoot. v.19 n. 3, 181-185, 1990.

MATIOLI, C.H.; MATIOLI, J.C.; ALMEIDA, A.A. Localização dos orifícios de emergência dos adultos de Sitophilus oryzae nos grãos de milho. Rev. Bras. De Armaz., Viçosa, v.13 e 14, n.1/2, 18-22, 1988/1989, p 22-24.

MIRANDA, M. M. M. et al. Detecção de não-preferência a Sitophilus zeamais Mots. em espigas e grãos de 49 populações de milho. Revista Brasileira de Armazenamento, Viçosa, v. 20, n. 1/2, p. 21-25, 1995.

PINTO JÚNIOR, A.R. Utilização de terra diatomácea no controle de pragas de armazenamento e domissanitárias. 1999, v.2 130p.Dissertação (Doutorado). Universidade Federal do Paraná. Curitiba.

PUZZI, D. Abastecimento e armazenagem de grãos. Campinas: Instituto Campineiro de Ensino Agrícola, 1986, p 246-247.

PUZZI, D. Abastecimento e armazenagem de grãos. Campinas: Instituto Campineiro de Ensino Agrícola, 2000, p. 149- 151; 314; 323.

SOLA, D. F. Atratividade de diferentes genótipos de milho ao gorgulho Sitophilus zeamais Mots em condições de laboratório. 1996. 21p. Trabalho de Conclusão de Curso (Graduação em Agronomia). Faculdade Dr. Francisco Maeda. Fundação Educacional de Ituverava 
Nucleus, v.6, n.2, out. 2009 